\title{
Examining the Role of Perceived Prestige in the Link Between Students' Subjective Socioeconomic Status and Sense of Belonging*
}

\author{
Mickaël Jury $^{1^{*}}$, Cristina Aelenei ${ }^{2}$, Chen Chen $^{3}$, Céline Darnon ${ }^{4}$ and Andrew J. Elliot ${ }^{5}$ \\ ${ }^{1}$ ESPE Lille Nord de France, ESPE Clermont Auvergne \\ ${ }^{2}$ Université Paris Descartes \\ ${ }^{3}$ Nanjing Normal University \\ ${ }^{4}$ Université Clermont Auvergne \\ ${ }^{5}$ University of Rochester
}

\begin{abstract}
Low socioeconomic status (SES) students have a lower sense of belonging to college than high SES students. Due to the importance of sense of belonging in the college pathway, understanding the reason for this relation is particularly important. Here, we argue that in addition to having less access to resources, low SES students in the college context also perceive themselves as having lower prestige than their high SES counterparts. Thus, in the present research, we tested perceived prestige as a mediator of the link between subjective SES and sense of belonging to college. We conducted three studies in two different countries (USA and China), and these investigations provided evidence that the lower students' subjective SES, the lower their self-attributed prestige, and that prestige mediated the relation between students' subjective SES and their sense of belonging to college. The implications of these findings for understanding the collegiate experience of low SES students are discussed.
\end{abstract}

Keywords: college, subjective socioeconomic status, sense of belonging, prestige

The need to feel socially connected to others is a fundamental aspect of human life (Baumeister \& Leary, 1995) and has crucial implications for psychological functioning (see Allen \& Kern, 2017) and physical health (see Cohen \& Janicki-Deverts, 2009). In educational contexts, sense of belonging to an educational community has been shown to have an impact on achievement, self-efficacy, well-being, and intrinsic motivation (Freeman, Anderman, \& Jensen, 2007; Ostrove \& Long, 2007; Pittman \& Richmond, 2007; Stebleton, Soria, \& Huesman, 2014; Walton \& Cohen, 2007, 2011; Yeager et al., 2016). Research has documented that in such contexts, the experience of sense of belonging not only depends on individual factors (e.g., self-esteem; Ma, 2003), but also on students' membership to different social groups. In particular, all things being equal, low socioeconomic status (SES) students experience a poorer sense of belonging to college than high SES students (Kim \& Sax, 2009; Ostrove \& Long, 2007; Reay, Crozier, \& Clayton, 2009; Ribera, Miller, \& Dumford, 2017; Rubin, 2012; Soria \& Stebleton, 2013; Soria, Stebleton, \& Huesman, 2013; Stebleton et al., 2014). However, how SES is related to students' sense of belonging remains unclear. The purpose of the present paper is to examine a potential mechanism underlying the association between SES and sense of belonging to college

\section{Students' SES and Sense of Belonging}

Why should SES impact students' sense of belonging to college? Existing research has documented the differential access to economic, material, social and personal resources as a potential explanation for the above association. For example, as compared to high SES students, low SES students have fewer economic resources and thus, more concerns about their financial situation. These concerns are likely to prevent low SES students from participating in social activities and experiencing social integration (Rubin \& Wright, 2017). In addition, since low SES students are usually older than high SES students, they often have to work offcampus and to take care of their family (Terenzini, Springer, Yaeger, Pascarella, \& Nora, 1996). Consequently, they have less time to devote to the college community and have fewer friends (Terenzini et al., 1996), which ultimately impairs their social integration (Rubin \& Wright, 2015, 2017). In addition, a recent line of research has shown that due to low familiarity with the cultural codes of higher education emphasizing independence, low SES students also have fewer

\footnotetext{
*This paper has been accepted for publication in Group Processes and Intergroup Relation. This version is a post-print.

${ }^{*}$ Corresponding author: Mickaël Jury, ESPE Clermont Auvergne, 36 avenue Jean Jaurès, 63400 Chamalières, France. Phone number: +334 733171 72. Email: mickael.jury@uca.fr
} 
personal resources (e.g., a more interdependentlyshaped self-construal) to meet the expectation of this environment than higher SES students (Stephens, Hamedani, \& Destin, 2014). All in all, this lack of economic, material, social, and personal resources are important explanations of the link between low SES students and a relatively poor sense of belonging to college.

In line with the analyses of Kraus and colleagues (Kraus, Piff, Mendoza-Denton, Rheinschmidt, \& Keltner, 2012), we argue that in addition to differential access to resources as a function of SES, students are attributed value and prestige on the basis of their SES that in turn is likely to impact their sense of belonging to the prestigious context of higher education. That is, individual differences among low and high SES individuals cannot be understood without considering the structural dynamic of society (Kraus \& Park, 2017). Indeed, one of the reasons why low and high SES individuals differ in terms of motivations and perceptions is that the hierarchical structure that these groups live in shapes their perceptions of the environment (for a review, see Kraus et al., 2012; see also Goudeau, Autin, \& Croizet, 2017). Thus, both high and low SES students develop perceptions that correspond to, justify, and reproduce the hierarchy of the society in which they live (Jost, Banaji, \& Nosek, 2004).

\section{The Prestige of High and Low SES Students in the College Context}

In our vertically hierarchized societies, an individual who seeks to reach the top of the hierarchy can use different strategies (Anderson, Hildreth, \& Howland, 2015; Cheng, Tracy, Foulsham, Kingstone, \& Henrich, 2013). Displaying "skills and knowledge valued by the group, which in turn, brings respect, admiration, and, ultimately, high social rank" (Maner, 2017) is one of them. In academia, those skills and knowledge refer to academic achievement or intelligence (Maner, 2017). In other words, a student who seeks to reach a high social rank must see his or her competence recognized by others (i.e., students and teachers). Such a recognition can be labeled as prestige. Indeed, prestige can be defined as the amount of recognition freely conferred to an individual by others as a consequence of his qualities and/or performances (see Barkow, 1989; Blader \& Chen, 2014; Bogardus, 1924; Goode, 1978; Henrich \& Gil-White, 2001; Leopold, 1913; Maner \& Case, 2016; Wegener, 1992).

As regularly suggested in the scientific literature, the social groups located at the bottom of the hierarchy (e.g., females, low SES individuals, ethnic minorities) suffer from a lack of recognition in comparison with those at the top (e.g., males, high
SES individuals, ethnic majorities, see Berger, Cohen, \& Zelditch, 1972; Blader \& Chen, 2014; Fiske, 2010). For example, low SES students are associated with important and recurrent negative stereotypes regarding their competence (see Cuddy et al., 2009; Durante \& Fiske, 2017; Fiske, Cuddy, Glick, \& Xu, 2002). These stereotypes result in poorer competence evaluations from their teachers (Baron, Albright, \& Malloy, 1995; Batruch, Autin, \& Butera, 2017; Darley \& Gross, 1983) and peers (Jonsson \& Beach, 2015; Régner, Huguet, \& Monteil, 2002; Varnum, 2013). In addition, beyond competence evaluation, low SES children have been shown to be less appreciated and less chosen as friends than high SES children, regardless of the perceiver's own SES (Shutts, Brey, Dornbusch, Slywotzky, \& Olson, 2016).

In line with earlier predictions of Cheng and Tracy (2013) regarding a positive link between SES and prestige, the above mentioned results suggest that a prestige gap exists between low and high SES students in education, and that this gap seems to be perceived by both high and low SES individuals (Durante, Tablante, \& Fiske, 2017). Indeed, people are likely to develop self-perceptions that match the position they occupy in a hierarchy (Jost, 2001; Jost et al., 2004). Thus, low SES individuals also have lower self-esteem (Kraus \& Park, 2014; Twenge \& Campbell, 2002), lower self-efficacy (RamosSánchez \& Nichols, 2007; Wiederkehr, Darnon, Chazal, Guimond, \& Martinot, 2015) and lower selfassessed intelligence (Ivcevic \& Kaufman, 2013), compared to their high SES counterparts, particularly when their belonging to a lower ranked group is made salient (Kudrna, Furnham, \& Swami, 2010). These mechanisms have led some authors to describe the self-concept of low SES individuals as an "undervalued self" (Kraus \& Park, 2014).

Since intelligence seems to be particularly important in order to determine one's prestige in the college context (Maner, 2017), we believe that the suggested prestige gap might particularly be true in this environment. Indeed, as regularly documented in the literature, low SES students are underrepresented in higher education in comparison with high SES students (Hearn \& Rosinger, 2014). This discrepancy means that the college context seems, by default, a high-SES environment, and that daily collegiate life entails constant reminders to low SES students of their minority status (Martin, 2015; Orbe, 2004). Several studies have documented that in such a context, low SES students experience an identity threat that strongly impacts their academic experience, including their sense of belonging (Browman \& Destin, 2016; Janke, Rudert, Marksteiner, \& Dickhäuser, 2017; Jury et al., 2017; Jury, Smeding, \& Darnon, 2015; Spencer \& Castano, 
2007; Stephens, Fryberg, Markus, Johnson, \& Covarrubias, 2012; Stephens, Townsend, Markus, \& Phillips, 2012). Altogether, these results suggest that in the college context, low SES students should perceive less prestige in the eyes of others (i.e., less recognition from them) than high SES students.

\section{Prestige and Sense of Belonging}

In order to feel connected with others, individuals need to feel safe regarding both their social relations with their peers (e.g., perceived similarity, familiarity, and trust; Zhao, Lu, Wang, Chau, \& Zhang, 2012) and their own identity. Recently, Cheng and colleagues (2010) demonstrated that the higher an individual's prestige in the eyes of others, the more social acceptance $\mathrm{s} / \mathrm{he}$ perceived from others. In a related way, Destin, Rheinschmidt-Same and Richeson (2017) demonstrated that the extent to which individuals feel uncertain regarding their status identity (i.e., "the subjective understanding, meaning, and value that people attach to their SES", p. 276) predicts their sense of belonging. More specifically, the more students are uncertain of their status identity, the less they feel socially connected with their peers. Since prestige is positively associated with social acceptance, in the present research, we hypothesized it as a mediator of the relation between students' SES and their sense of belonging to college. In other words, we expect low (vs. high) SES students to have self-perceptions that match the place their group occupies in the hierarchy, and thus, to have low (vs. a high) self-attributed prestige. In turn, the lower one's own perceived prestige, the lower his or her sense of belonging is expected to be. We conducted three studies to test the hypothesized indirect effect, namely, that the positive relation between students' SES and sense of belonging to college can be explained by students' perception of prestige. $^{\dagger}$

\section{Method}

\section{Study 1}

Participants. Two hundred and thirty-five U.S. undergraduates participated in the study (104 males and 131 females; $\left.M_{\text {age }}=19.36, S D=1.35\right)$. The sample size for this study (and the subsequent studies) represents the maximum number of participants that were available within the time frame established for using the university participant pool. Ethnicity was 49\% Caucasian, 6\% African American, 30\% Asian, 8\% Hispanic, and 7\% other or unspecified.
Procedure and materials. Participants completed the measures online during the first three weeks of the spring semester.

Participants' SES. Subjective SES is known to be a particularly powerful predictor (more than other SES measures) of psychological outcomes (e.g., mental health, see Adler, Epel, Castellazzo, \& Ickovics, 2000), including our main dependent variable, sense of belonging (see Bond et al., 2007; Stebleton et al., 2014). As a result, participants' subjective representation of their SES was measured using the MacArthur Scale of Subjective Social Status (Adler et al., 2000). Participants were asked to indicate their perceived position on a 10-runged "social ladder" in which higher rungs represent people who have higher SES in terms of income, education, and occupation in relation to other people $(M=6.16, S D=1.86)$. It should be noted that this measure focuses specifically on subjective SES, and results should be interpreted accordingly.

Perceived prestige. Participants' perceived prestige was measured with Cheng et al.'s (2010) measure. This measure was chosen for its good convergent and discriminant validity (Cheng, Weidman, \& Tracy, 2014), and is comprised of nine items assessing individuals' perceived prestige (e.g., "I am held in high esteem by those I know," "My unique talents and abilities are recognized by others"). Participants indicated, on a 1 (not at all) to 7 (extremely) scale, the extent to which the statements accurately described them $(\alpha=.83, M=$ $5.15, S D=0.84$ ). It should be noted that we have opted for a general framing of the perceived prestige measure instead of a specific one because we believe SES not only confers prestige in the context of University, but also prestige in society in general.

Sense of belonging. Participants completed a 17item measure assessing their sense of belonging to college (Walton \& Cohen, 2007). They used a 1 (strongly disagree) to 7 (strongly agree) scale $(\alpha=$ .92; $M=4.99, S D=0.90)$ to indicate the extent to which they agreed with the sentences provided (e.g., "I fit in well at [name of the university]," "I feel comfortable at [name of the university]"). Intercorrelations among the variables of interest are presented in Table 1.

\section{Results and Discussion}

All of the variables were standardized. Full information maximum likelihood method was used for analyses to avoid loss of information due to missing data (Enders, 2006). All data were analyzed using the Lavaan package (Rosseel, 2012) for R (R

\footnotetext{
${ }^{+}$All material and data can be accessed at: osf.io/2uq4y.
} 
Core Team, 2014). The data for this study, as well as for Studies 2 and 3, were collected in the context of larger projects; none of the findings from the research herein have been presented in any prior work. ${ }^{\$ 2}$ In this and all subsequent studies in this research, no data exclusions were used, all data were collected before any analyses were conducted, and all variables analyzed are reported.

We tested the hypothesized model (see Figure 1). Results revealed that participants' subjective SES positively predicted their sense of belonging, $\beta=.17$, $z=2.56, p=.010,95 \%$ CI $[.03, .29]$, and perceived prestige, $\beta=.14, z=2.21, p=.027,95 \%$ CI $[.01$, .27]; the higher one's subjective SES, the higher his or her perceived prestige and the more he or she felt a sense of belonging to his or her university. In addition, the higher the perceived prestige, the higher the sense of belonging, $\beta=.46, z=7.94, p<.001$, $95 \%$ CI $[.34, .57]$. Testing perceived prestige as a mediator revealed a significant indirect effect, $\beta=$ $.07, z=2.13, p=.033,95 \%$ CI $[.005, .12]$, confirming that the lower sense of belonging experienced by students who perceive their SES as low could be partially explained by their lower perceived prestige. It should be noted that the direct effect of SES on sense of belonging remained marginally significant, $\beta=.10, z=1.70, p=.088$, $95 \%$ CI $[-.01, .21]$.

This study provided evidence indicating that the lower students' subjective SES, the lower their sense of belonging to college. The present results also indicated that this link could be explained by students' perceived prestige, suggesting an interpretation of the differences among low and high SES students in college in terms of group value (Kraus \& Park, 2017). Study 2 was conducted to seek to replicate these results while controlling for students' level of academic achievement. Indeed, one may argue that the positive relations of students' subjective SES to their perceived prestige and sense of belonging may actually be due to their shared association with their actual academic achievement. Level of achievement has been shown to predict sense of belonging (e.g., Soria \& Stebleton, 2013; Walton \& Cohen, 2007). Thus, the results of Study 1 may simply indicate that high achievers (who are often higher SES students; Koza Çiftiçi \& Melis Cin, 2017) have both more prestige in college and more sense of belonging. Replicating the results while controlling for the influence of students' level of academic achievement would enable us to rule out this explanation.

\section{Study 2}

\section{Method}

Participants. Three hundred and twenty-seven U.S. undergraduates participated in the study (204 females, 123 males; $M_{\text {age }}=19.69$ years, $S D=1.69$ ). Ethnicity was $43 \%$ Caucasian, $6 \%$ African American, 32\% Asian, 10\% Hispanic, and 9\% other or unspecified.

Procedure and materials. Participants' subjective SES $(M=6.03, S D=1.87)$, perceived prestige $(\alpha=.82, M=5.07, S D=0.85)$ and sense of belonging $(\alpha=.92, M=4.88, S D=0.92)$ were assessed in the same way as used in Study 1. Participants' level of academic achievement was estimated based on their self-reported Grade Point Average $(M=3.30, S D=0.50)$. As in Study 1, the questionnaire was completed during the first few weeks of the spring semester. Intercorrelations among the variables are presented in Table 1.

Table 1

Intercorrelations among variables in Study 1, Study 2, and Study 3

\begin{tabular}{lccc}
\hline & 1 & 2 & 3 \\
\hline & $\mathrm{S} 1 / \mathrm{S} 2 / \mathrm{S} 3$ & $\mathrm{~S} 1 / \mathrm{S} 2 / \mathrm{S} 3$ & $\mathrm{~S} 1 / \mathrm{S} 2 / \mathrm{S} 3$ \\
1. Subjective SES & - & & \\
2. Perceived prestige & $.15^{*} / .29^{* *} / .22^{* *}$ & - & \\
3. Sense of belonging & $.16^{*} / .28^{* *} / .12^{* *}$ & $.47^{* *} / .53^{* *} / .65^{* *}$ & - \\
$\begin{array}{l}\text { 4. Level of academic } \\
\text { achievement }\end{array}$ & N.A. $/ .37^{* *} / .10^{t^{*}}$ & N.A. $/ .13^{*} / .20^{* *}$ & N.A. $/ .32^{* *} / .17^{* *}$ \\
\hline
\end{tabular}

Note. ${ }^{\mathrm{t}} p<.10,{ }^{*} p<.05,{ }^{* *} p<.001$. N.A.: Not applicable

\footnotetext{
${ }^{\ddagger}$ For Study 1, see Wallace and Elliot (2018, Study 2); for Study 2, see Korn, Daumiller, and Elliot (2018, Study 2).
} 


\section{Results and Discussion}

The regression model included all of the variables of Study 1, plus the level of academic achievement. Because none of the interactions involving students' self-reported level of achievement were significant in the preliminary analyses, these ones were removed from the final model (Yzerbyt, Muller, \& Judd, 2004).

Results revealed that participants' subjective SES, $\beta=.19, z=3.36, p=.001,95 \%$ CI $[.07, .29]$, and level of achievement, $\beta=.25, z=4.43, p=.001$, $95 \%$ CI $[.13, .35]$, significantly predicted their sense of belonging to college. Participants' subjective SES also significantly predicted their perceived prestige, $\beta=.28, z=4.86, p<.001,95 \%$ CI $[.16, .39]$; academic achievement was not related to perceived prestige, $\beta=.02, z=0.37, p=.71,95 \%$ CI $[-.09, .13]$. In addition, the higher the perceived prestige, the higher the sense of belonging, $\beta=.49, z=10.52, p<$ $.001,95 \%$ CI $[.39, .58]$. Finally, the indirect effect was significant, $\beta=.14, z=4.40, p<.001,95 \% \mathrm{CI}$ $[.07, .19]$, while the direct effect was no longer significant, $\beta=.05, z=1.02, p=.31,95 \%$ CI [-.04, .14] (see Figure 1).

These results indicate that regardless of their level of academic achievement, students' subjective SES is positively associated with their sense of belonging and that this link can be explained by perceived prestige. Thus, these findings both replicate those of Study 1 and address the third variable explanation grounded in level of academic achievement.

Despite the consistent results obtained in the first two studies, we identified two limitations. First, as with most studies in psychological science, these studies were conducted in a Western, Educated, Industrialized, Rich, and Democratic (i.e., WEIRD) society. As noted by Henrich, Heine, and Norenzayan (2010), U.S. undergraduates have been overstudied and the use of more diverse subject pools can strengthen the confidence in research findings. As recently shown by Chiu, Chow, Mcbride, and Mol (2016), sense of belonging in school varies across cultures, with students in more egalitarian cultures having a higher sense of belonging in school compared to students in more hierarchical cultures (see Hofstede's, 2011, power distance cultural dimension). Moreover, research has also documented that whereas Western countries are typically low in power distance, Asian countries are typically high in power distance (i.e., the unequal distribution of power is accepted as natural, its legitimacy being irrelavant; Hofstede, 2011). Thus, testing the link between subjective SES and sense of belonging in a Chinese sample is a good way to see if our findings could generalize outside of the American context.

Second, in our first two studies, participants started with the completion of the subjective SES measure. This may have activated their stigmatized identity, thereby triggering a social identity threat for those who perceived their SES as low (Clark, Thiem, Barden, Stuart, \& Evans, 2015; Danaher \& Crandall, 2008; Kudrna et al., 2010). This might be at least partially responsible for the association between subjective SES and both perceived prestige and sense of belonging.

In this regard, Study 3 had two goals. First, Study 3 aimed to replicate the results obtained in Studies 1 and 2 with a different sample, specifically a sample from a high power distance culture (i.e., China). Second, in Study 3 subjective SES was assessed either before or after the perceived prestige and sense of belonging measures to determine whether the order of assessment had any impact on the focal variables and findings. As in Study 1 and 2, an indirect effect of subjective SES on sense of belonging, via perceived prestige, was anticipated.

\section{Study 3}

\section{Method}

Participants. Three hundred and ninety-four Chinese students participated in the study (304 females, 90 males; $M_{\text {age }}=20.64$ years, $S D=1.62$ ). Participants came from four different universities, and most majored in the Social Sciences (i.e., 85\%).

Procedure and materials. Participants completed a questionnaire during one of the last weeks of the spring semester. Participants' subjective SES was assessed with the same instrument as in Studies 1 and 2. However, because of differences in self-construal (with Chinese individuals having a more interdependent self than Americans; see Oyserman, Coon, \& Kemmelmeier, 2002, for a meta-analysis), participants were asked to indicate where their family stands on this scale (instead of themselves, as in Studies 1 and 2; $M=$ 5.14, $S D=1.46$ ). Participants were randomly assigned to one of two order conditions. In one condition, $(n=128)$ participants started the questionnaire with the subjective SES measure ("SES-first" condition); in the other $(n=266)$, participants finished the questionnaire with the subjective SES measure ("SES-final" condition). Participants' perceived prestige ( $\alpha=.82 ; M=4.89$, $S D=0.76)$ and sense of belonging $(\alpha=.90 ; M=$ $4.64, S D=0.77$ ) were measured in the same way as in the previous studies. All measures were first translated into participants' first language, Mandarin, by a native speaker and were then back-translated into English by other bilingual researchers. These 
back-translated items were compared to the original items and validated by a fourth expert. Participants' academic achievement was collected through a selfreport measure of students' average score (out of $100)$ the last semester $(M=85.19, S D=5.87)$. Intercorrelations among the variables are presented in Table 1.

\section{Results and Discussion}

The regression model included four predictors: participants' subjective SES (mean-centered), experimental condition (coded -0.5 for the SES-final condition and +0.5 for the SES-first condition), the interaction between these two predictors, and participants' level of achievement (mean-centered). As in Study 2, since none of the interactions involving participants' level of achievement were significant in the preliminary analyses, they were removed from the final model (Yzerbyt et al., 2004).

Sense of belonging. Neither the main effect of experimental condition, $\beta=.05, z=1.06, p=.29$, $95 \%$ CI $[-.04, .15]$, nor its interaction with subjective SES, $\beta=-.08, z=-1.50, p=.13,95 \%$ CI $[-.19, .02]$ were significant. Unexpectedly, the main effect of participants' subjective SES was not significant either, although it was in the expected direction, $\beta=$ $.07, z=1.18, p=.24,95 \%$ CI $[-.04, .17]$. Only the level of achievement significantly predicted sense of belonging to college, $\beta=.17, z=3.30, p=.001,95 \%$ CI $[.06, .26]$.

Perceived prestige. A main effect of experimental condition, $\beta=.11, z=2.17, p=.030,95 \%$ CI $[.01$, $.20]$, indicated that participants who started with the subjective SES measure $(M=5.00, S E=.06)$ perceived their prestige as higher than participants who finished with the subjective SES measure $(M=$ 4.83, $S E=.04)$. In addition, participants' subjective SES, $\beta=.17, z=3.10, p=.002,95 \%$ CI $[.06, .27]$, and level of achievement, $\beta=.19, z=3.80, p<.001$, $95 \%$ CI $[.09, .28]$, significantly and positively predicted perceived prestige. The interaction between participants' subjective SES and the experimental condition was not significant, $\beta=-.05$, $z=-0.85, p=.40,95 \%$ CI $[-.15 ; .05]$.

Test of the indirect effect. The presence of a total effect (i.e., the main effect of students' subjective SES on sense of belonging) is not a precondition for

\footnotetext{
$\S$ Due to potential links between students' SES, gender, and age (i.e., low SES students are more likely to be older and female, see Giancola, Munz, \& Trares, 2008; Rubin \& Wright, 2015), as well as established links between students' ethnicity and students' university pathways (Walton \& Cohen, 2007), the analyses in the three studies were replicated controlling for these variables (except for Study 3 in which the latter was not collected). The results
}

testing the presence of a hypothesized indirect effect (see Hayes, 2009), and the results indicated that the higher ones' perceived prestige, the higher his or her sense of belonging, $\beta=.65, z=16.28, p<.001,95 \%$ CI $[.57, .72]$. Thus, further analyses were conducted to test the hypothesized indirect effect linking students' subjective SES to their sense of belonging through perceived prestige. This indirect effect was significant, $\beta=.11, z=3.04, p=.002,95 \%$ CI [.03, $.17]$, whereas the direct effect was not, $\beta=-.04, z=$ $-1.00, p=.32,95 \%$ CI $[-.12, .04]$ (see Figure 1). ${ }^{\S}$

To sum up, the present findings suggest that, in a new context, regardless of their level of academic achievement, students' subjective SES is linked to their sense of belonging to college through their perceived prestige. As such, the results replicate the key findings of Study 2. It is worth noting that the order of the SES measure did not moderate the effect of subjective SES on perceived prestige (i.e., $\beta=$ $.05, z=-0.85, p=.40,95 \%$ CI $[-.15, .05])$, nor the partial effect on sense of belonging (i.e., $\beta=.09, z=$ $0.97, p=.33,95 \%$ CI $[-.08, .25])$. Therefore, the mediation is not moderated (Muller, Judd, \& Yzerbyt, 2005). Moreover, the difference in the indirect effect between the two levels of the experimental condition (Mediation package in $\mathrm{R}$, Tingley, Yamamoto, Hirose, Keele, \& Imai, 2014), was not significant $(p=.53,95 \%$ CI $[-.09, .05])$, providing further evidence that the relations in the model do not depend on subjective SES salience.

Interestingly, it should be noted that the participants who started with the SES measure perceived their prestige as higher than participants who finished with the SES measure. We think that this may be because the measure of subjective SES was in reference to the perception of family rank, which beside capturing SES, also possibly rendered students' family ties more salient. This family salience may have increased for all students, independent of their SES, the extent to which they felt respected and approved of others.

Ancillary analysis. As the total effect of students' subjective SES on sense of belonging was not significant in this third study, we conducted a random-effect meta-analysis in $\mathrm{R}$ using the 'Metafor' package (Viechtbauer, 2010) to investigate the reliability of this link across the three studies. We used the Sidik-Jonkman method, which

were unaffected: The total effects $\left(p_{\mathrm{S} 1}=.011 ; p_{\mathrm{S} 2}<.001\right.$; $\left.p_{\mathrm{S} 3}=.14\right)$, as well as the indirect effects $\left(p_{\mathrm{S} 1}=.009 ; p_{\mathrm{S} 2}<\right.$ $.001 ; p_{\mathrm{s} 3}=.001$ ), were approximately the same. It should be noted that ethnicity was significantly related to prestige in studies 1 and $2\left(p_{\mathrm{S} 1}=.008 ; p_{\mathrm{S} 2}=.025\right)$ and that age was significantly related to prestige $(p=.001)$ and sense of belonging in Study $3(p=.009)$. Interested readers may conduct their own analyses on the available datasets. 
is preferred for meta-analyses including a small number of studies (Inthout, Ioannidis, \& Borm, 2014). This analysis confirmed the positive link between students' subjective SES and their sense of belonging, $B=0.14, S E=0.04, Z=3.24, p=.001$, $95 \%$ CI [0.05, 0.22]. Moreover, estimates for heterogeneity showed low heterogeneity across studies, $T^{2}=0.002, I^{2}=0.31$, and $Q(\mathrm{df}=2)=2.24$, $p=.33$.

\section{General Discussion}

Sense of belonging to an educational community has a crucial impact on a number of important educational outcomes (e.g., achievement, motivation, well-being, see Freeman et al., 2007; Ostrove \& Long, 2007; Pittman \& Richmond, 2007; Stebleton et al., 2014). Importantly, this sense of belonging is not equal across groups in the college context; with previous research consistently demonstrating that low SES students experience a poorer sense of belonging to college than high SES students (Kim \& Sax, 2009; Ostrove \& Long, 2007; Rubin, 2012; Stebleton et al., 2014). This prior research has also documented that differential access to economic, material, social, and personal resources explains this effect (Rubin \& Wright, 2015; 2017; see also Johnson, Richeson, \& Finkel, 2011). In the present research, we use a structural analysis of social class (see Kraus \& Park, 2017; Kraus, et al., 2012) to examine whether the difference in perceived prestige between low and high (subjective) SES students could contribute to explain the difference in sense of belonging. That is, the purpose of the present work was to examine correlational evidence for the hypothesis that perceived prestige could be a mechanism explaining the link between students' subjective SES and their sense of belonging to college.

The results obtained in the three studies supported this mediational hypothesis. Indeed, they confirmed that, regardless of their level of academic achievement, students' subjective SES positively predicts their sense of belonging to college and that this link could be explained by the prestige that students feel they have in the eyes of others. This result is consistent with recent research findings showing that in the college context, even the most competent low SES students face important uncertainty regarding their recognition by others (see Destin et al., 2017), an uncertainty that is likely to generate several negative outcomes in college (see Croizet \& Claire, 1998; John-Henderson, Rheinschmidt, Mendoza-Denton, \& Francis, 2014; Jury et al., 2017; Spencer \& Castano, 2007).

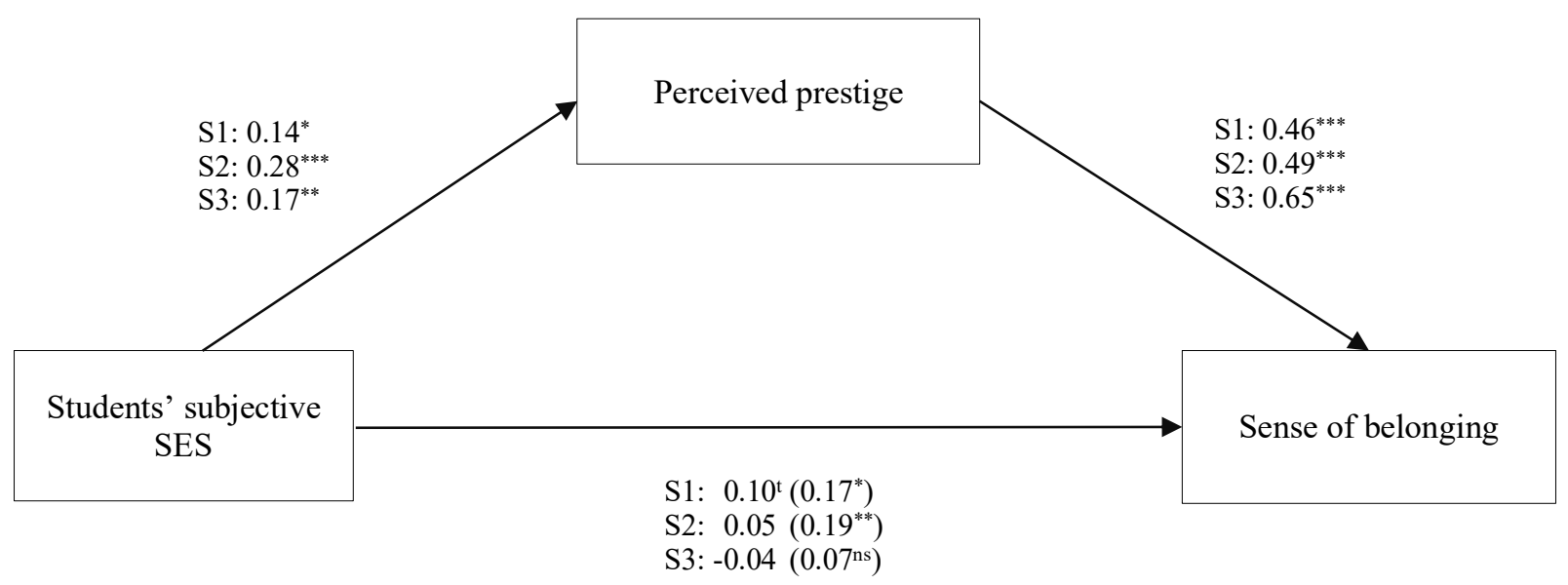

Figure 1. Indirect effect of participants' subjective SES on sense of belonging through perceived prestige (Values indicate standardized regression coefficients, $\beta$, with and without — in brackets - controlling perceived prestige. S1: Study 1, S2: Study 2, S3: Study 3. $\left.{ }^{n s} p>.10,{ }^{t} p<.10,{ }^{*} p<.05 ;{ }^{* *} p<.01 ;{ }^{* * *} p<.001\right)$. 
Furthermore, we investigated this mediational mechanism in culturally diverse samples that differed with regard to power distance, which has been shown to have an impact on sense of belonging (Chiu et al., 2016). Results showed that the observed relation between students' subjective SES and sense of belonging through perceived prestige also exists outside the American context. Studying the antecedents of students' sense of belonging in a Chinese sample is particularly timely, given the relatively new emphasis on mass education in contemporary China, and the subsequent social class achievement gaps that are emerging, accordingly (Mok \& Wu, 2016).

Some limitations of this work should be noted. First, the present studies were correlational and imply that causality cannot be generated. In particular, on the basis of the present results, one cannot exclude the possibility that the low level of prestige perceived by students' who appraised their SES as low could actually be explained by their lower sense of belonging to college instead of the opposite relation. To address this issue, it would be valuable in future research to manipulate students' subjective SES and prestige (e.g., Kraus, Horberg, Goetz, \& Keltner, 2011) or to conduct a longitudinal study. In addition, to extend the present work by using a behavioral measure of students' actual social belonging (e.g., involvement in the college community, number of extra-curriculum activities) would nicely complement these data. Second, an integrative approach simultaneously testing the two mediational paths from students' subjective SES to sense of belonging, namely through resources (either economic, material, or personal) and prestige, would help to separate the unique contribution of each mediator. Third, it should be acknowledged that there is a conceptual proximity between subjective SES and perceived prestige. Indeed, even if subjective SES and prestige capture different meanings (social standing for SES, recognition freely conferred to an individual by others, for prestige), both constructs are related to the notion of general social status. The weak to moderate correlations between the two measures observed in all three studies $(.15<r<.29)$, combined with earlier work showing that the constructs have distinct consequences on several outcomes (e.g., Anderson, Kraus, Galinsky, \& Keltner, 2012; Krueger, Tran, Saint Onge, \& Rogers, 2016), support the distinctiveness of these constructs. However, it remains possible that the similarity between the SES and prestige measures could at least partially explain their association in the present research. For this reason, replicating the results with another (more objective) measure of SES would reinforce our interpretation. Finally, it should be acknowledged that the results obtained here did not reflect the effect of SES per se, but only the effect of its subjective component, and conclusions should be drawn with this in mind.

Research examining the influence of students' SES in the college context has received increased attention recently (Jury et al., 2017). Designing interventions in order to help these students reach a higher level of achievement is of great concern for researchers and practitioners alike (Harackiewicz et al., 2014; Harackiewicz, Canning, Tibbetts, Priniski, \& Hyde, 2016; Stephens et al., 2014; Yeager et al., 2016). Interestingly, many of the interventions that have been successfully tested thus far specifically address the lower sense of belonging that low SES students experience in higher education. For example, in a large-scale intervention, Yeager et al. (2016) had first-year college students read stories about older student's struggles when transitioning to college. The stories were designed to highlight two main points. First, that almost everyone, regardless of their background characteristics, experiences difficulty and questions their belonging to college and, second, that students can overcome these challenges by creating social ties to other individuals in their college. The results showed that the disadvantaged students participating in the intervention were more likely to feel integrated within the college context and, ultimately, reached a higher level of achievement than those in the control group. In the same vein, the present research emphasizes how important it is that students experience a strong sense of belonging to college, and that perceived prestige could have an important role. Thus, to improve low SES students' sense of belonging, a future intervention could focus on overcoming specific barriers in terms of perceived prestige. For instance, based on a similar kind of intervention (see Stephens et al., 2014), first-year college students could be invited to a panel discussion in which former successful low and high SES students share thoughts and feelings about their college experience. Throughout the discussion, low SES panelists could mention how they struggled at the beginning with their perception that others did not particularly recognize their qualities and/or performances and how they eventually overcame this obstacle to finally succeed.

From a general standpoint, understanding the mechanisms, such as perceived prestige, that could explain low SES students' lower level of sense of belonging is particularly of value. It opens up a deeper understanding of the psychological barriers faced by low SES students in the college context, and facilitates ideas for the development of interventions that may ultimately help these students to increase their level of achievement and success. 


\section{Declaration of Conflicting Interests}

The authors declare that there are no potential conflicts of interest with respect to the research, authorship, and/or publication of this article.

\section{References}

Adler, N. E., Epel, E. S., Castellazzo, G., \& Ickovics, J. R. (2000). Relationship of subjective and objective social status with psychological and physiological functioning: Preliminary data in healthy White women. Health Psychology, 19(6), 586-592. doi:10.1037/0278-6133.19.6.586

Allen, K.-A., \& Kern, M. L. (2017). The need to belong. In K.-A. Allen \& M. L. Kern (Eds.), School Belongings in Adolescents (pp. 5-12). Singapore: Springer. doi:10.1007/978-981-10-5996-4_2

Anderson, C., Hildreth, J. A. D., \& Howland, L. (2015). Is the desire for status a fundamental human motive? A review of the empirical literature. Psychological Bulletin, 141(3), 574-601. doi:10.1037/a0038781

Anderson, C., Kraus, M. W., Galinsky, A. D., \& Keltner, D. (2012). The local-ladder effect social status and subjective well-being. Psychological Science, 23(7), 764-771. doi:10.1177/0956797611434537

Barkow, J. H. (1989). Darwin, sex, and status: Biological approaches to mind and culture. (J. H. Barkow, Ed.). Toronto, ON, Canada: University of Toronto Press.

Baron, R. M., Albright, L., \& Malloy, T. E. (1995). Effects of behavioral and social class information on social judgement. Personality and Social Psychology Bulletin, 21(4), 308-315. doi:10.1177/0146167295214001

Batruch, A., Autin, F., \& Butera, F. (2017). Reestablishing the social-class order: Restorative reactions against high-achieving, low-SES pupils. Journal of Social Issues, 73(1), 42-60. doi:10.1111/josi.12203

Baumeister, R. F., \& Leary, M. R. (1995). The need to belong: Desire for interpersonal attachments as a fundamental human motivation. Psychological Bulletin, 117(3), 497-529. doi:10.1037/00332909.117.3.497

Berger, J., Cohen, B. P., \& Zelditch, M. (1972). Status characteristics and social interaction. American Sociological Review, 37(3), 241-255. Retrieved from http://www.jstor.org/stable/2093465

Blader, S. L., \& Chen, Y. (2014). What's in a name? Status, power, and other forms of social hierarchy. In J. T. Cheng, J. L. Tracy, \& C. Anderson (Eds.), The Psychology of Social Status (pp. 71-95). New York: Springer. doi:10.1007/978-1-4939-0867-7

Bogardus, E. S. (1924). Fundamentals of Social Psychology. New York: Century.

Bond, L., Butler, H., Thomas, L., Carlin, J., Glover, S., Bowes, G., \& Patton, G. (2007). Social and school connectedness in early secondary school as predictors of late teenage substance use, mental health, and academic outcomes. Journal of Adolescent Health, 40, 9-18. doi:10.1016/j.jadohealth.2006.10.013

Browman, A. S., \& Destin, M. (2016). The effects of a warm or chilly climate toward socioeconomic diversity on academic motivation and self-concept. Personality and Social Psychology Bulletin, 42(2),
172-187. doi:10.1177/0146167215619379

Cheng, J. T., \& Tracy, J. L. (2013). The impact of wealth on prestige and dominance rank relationships. Psychological Inquiry, 24(2), 102-108. doi:10.1080/1047840X.2013.792576

Cheng, J. T., Tracy, J. L., Foulsham, T., Kingstone, A., \& Henrich, J. (2013). Two ways to the top: evidence that dominance and prestige are distinct yet viable avenues to social rank and influence. Journal of Personality and Social Psychology, 104(1), 103-25. doi: $10.1037 / \mathrm{a} 0030398$

Cheng, J. T., Tracy, J. L., \& Henrich, J. (2010). Pride, personality, and the evolutionary foundations of human social status. Evolution and Human Behavior, 31 , doi:10.1016/j.evolhumbehav.2010.02.004

Cheng, J. T., Weidman, A. C., \& Tracy, J. L. (2014). The assessment of social status: A review of measures and experimental manipulations. In J. T. Cheng, J. L. Tracy, \& C. Anderson (Eds.), The Psychology of Social Status (pp. 347-362). New York: Springer.

Chiu, M. M., Chow, B. W., Mcbride, C., \& Mol, S. T. (2016). Students' sense of belonging at school in 41 countries : Cross-cultural variability. Journal of CrossCultural Psychology, 47(2), 175-196. doi: $10.1177 / 0022022115617031$

Clark, J. K., Thiem, K. C., Barden, J., Stuart, J. O. R., \& Evans, A. T. (2015). Stereotype validation: The effects of activating negative stereotypes after intellectual performance. Journal of Personallity and Social Psychology, 108(4), 531-552. doi:10.1037/a0038887

Cohen, S., \& Janicki-Deverts, D. (2009). Can we improve our physical health by altering our social networks? Perspectives on Psychological Science, 4(4), 375-378. doi:10.1111/j.1745-6924.2009.01141.x.

Croizet, J.-C., \& Claire, T. (1998). Extending the concept of stereotype threat to social class: The intellectual underperformance of students from low socioeconomic backgrounds. Personality and Social Psychology Bulletin, 24(6), 588-594. doi: $10.1177 / 0146167298246003$

Cuddy, A. J. C., Fiske, S. T., Kwan, V. S. Y., Glick, P., Demoulin, S., Leyens, J.-P., ... Ziegler, R. (2009). Stereotype content model across cultures: Towards universal similarities and some differences. British Journal of Social Psychology, 48(1), 1-33. doi:10.1348/014466608X314935

Danaher, K., \& Crandall, C. S. (2008). Stereotype threat in applied settings re-examined. Journal of Applied Social Psychology, 38(6), 1639-1655. doi:10.1111/j.1559-1816.2008.00362.x

Darley, J. M., \& Gross, P. H. (1983). A hypothesisconfirming bias in labeling effects. Journal of Personality and Social Psychology, 44(1), 20-33. doi:10.1037//0022-3514.44.1.20

Destin, M., Rheinschmidt-Same, M., \& Richeson, J. A. (2017). Status-based identity: A conceptual approach integrating the social psychological study of socioeconomic status and identity. Perspectives on Psychological Science, 12(2), 270-289. doi:10.1177/1745691616664424

Durante, F., \& Fiske, S. T. (2017). How social-class stereotypes maintain inequality. Current Opinion in $\begin{array}{lll}\text { Psychology, } & 18, & 43-48 .\end{array}$ 
doi:10.1016/j.copsyc.2017.07.033

Durante, F., Tablante, C. B., \& Fiske, S. T. (2017). Poor but warm, rich but cold (and competent): Social classes in the stereotype content model. Journal of Social Issues, 73(1), 138-157. doi:10.1111/josi.12208

Enders, C. K. (2006). A primer on the use of modern missing-data methods in psychosomatic medicine research. Psychosomatic Medicine, 68(3), 427-436. doi:10.1097/01.psy.0000221275.75056.d8

Fiske, S. T. (2010). Interpersonal stratification. Status, power and subordination. In S. T. Fiske, D. T. Gilbert, \& G. Lindzey (Eds.), Handbook of Social Psychology (pp. 941-982). Hoboken, NJ US: John Wiley \& Sons. doi:10.1002/9780470561119.socpsy002026

Fiske, S. T., Cuddy, A. J. C., Glick, P., \& Xu, J. (2002). A model of (often mixed) stereotype content: Competence and warmth respectively follow from perceived status and competition. Journal of Personality and Social Psychology, 82(6), 878-902. doi:10.1037//0022-3514.82.6.878

Freeman, T. M., Anderman, L. H., \& Jensen, J. M. (2007). Sense of belonging in college freshmen at the classroom and campus levels. The Journal of Experimental Education, 75(3), 203-220. doi:10.3200/JEXE.75.3.203-220

Giancola, J. K., Munz, D. C., \& Trares, S. (2008). Firstversus continuing-generation adult students on college perceptions: Are differences actually because of demographic variance? Adult Education Quarterly, 58(3), 214-228. doi:10.1177/0741713608314088

Goode, W. (1978). The celebration of heroes: Prestige as a control system. Berkely, CA: University of California Press.

Goudeau, S., Autin, F., \& Croizet, J.-C. (2017). Etudier, mesurer et manipuler la classe sociale en psychologie sociale: Approches économiques, symboliques et culturelles [Studying, measuring and manipulating social class in social psychology: Economic, symbolic and cultural approaches]. International Review of Social Psychology, 30(1), 1-19. doi:10.5334/irsp.52

Harackiewicz, J. M., Canning, E. a., Tibbetts, Y., Giffen, C. J., Blair, S. S., Rouse, D. I., \& Hyde, J. S. (2014). Closing the social class achievement gap for firstgeneration students in undergraduate biology. Journal of Educational Psychology, 106(2), 375-389. doi:10.1037/a0034679

Harackiewicz, J. M., Canning, E. A., Tibbetts, Y., Priniski, S. J., \& Hyde, J. S. (2016). Closing achievement gaps with a utility-value intervention: Disentangling race and social class. Journal of Personality and Social Psychology, 111(5), 745-765. doi: $10.1037 /$ pspp0000075

Hayes, A. F. (2009). Beyond Baron and Kenny : Statistical mediation analysis in the new millennium. Communication Monographs, 76(4), 408-420. doi:10.1080/03637750903310360

Hearn, J. C., \& Rosinger, K. O. (2014). Socioeconomic diversity in selective private colleges: An organizational analysis. The Review of Higher Education, 38(1), 71-104. doi:10.1353/rhe.2014.0043

Henrich, J., \& Gil-White, F. J. (2001). The evolution of prestige: Freely conferred deference as a mechanism for enhancing the benefits of cultural transmission. Evolution and Human Behavior, 22(3), 165-196.
doi:10.1016/S1090-5138(00)00071-4

Henrich, J., Heine, S. J., \& Norenzayan, A. (2010). The weirdest people in the world? Behavioral and Brain Sciences, 33(2), 1-75. doi:10.1017/S0140525X0999152X

Hofstede, G. (2011). Dimensionalizing cultures: The Hofstede model in context. Online Readings in Psychology and Culture, 2(1). doi:https://doi.org/10.9707/2307-0919.1014

Inthout, J., Ioannidis, J. P. A., \& Borm, G. F. (2014). The Hartung-Knapp-Sidik-Jonkman method for random effects meta-analysis is straightforward and considerably outperforms the standard DerSimonianLaird method. BMC Medical Research Methodology, 14:25, 1-12. doi:10.1186/1471-2288-14-25

Ivcevic, Z., \& Kaufman, J. C. (2013). The can and cannot do attitude: How self-estimates of ability vary across ethnic and socioeconomic groups. Learning and Individual Differences, 27, 144-148. doi:10.1016/j.lindif.2013.07.011

Janke, S., Nitsche, S., Praetorius, A. K., Benning, K., Fasching, M., Dresel, M., \& Dickhäuser, O. (2016). Deconstructing performance goal orientations: The merit of a dimensional approach. Learning and Individual Differences, 50, 133-146. doi:10.1016/j.lindif.2016.08.013

John-Henderson, N. A., Rheinschmidt, M. L., MendozaDenton, R., \& Francis, D. D. (2014). Performance and inflammation outcomes are predicted by different facets of SES under stereotype threat. Social Psychological and Personality Science, 5(3), 301309. doi:10.1177/1948550613494226

Johnson, S. E., Richeson, J. A., \& Finkel, E. J. (2011). Middle class and marginal? Socioeconomic status, stigma, and self-regulation at an elite university. Journal of Personality and Social Psychology, 100(5), 838-852. doi:10.1037/a0021956

Jonsson, A.-C., \& Beach, D. (2015). Institutional discrimination: Stereotypes and social reproduction of "class" in the Swedish upper-secondary school. Social Psychology of Education, 18, 703-717. doi:10.1007/s11218-014-9279-1

Jost, J. T. (2001). Outgroup favoritism and the theory of system justification: A paradigm for investigating the effects of socioeconomic success on stereotype content. In G. B. Moskowitz (Ed.), Cognitive social psychology: The Princeton Symposium on the Legacy and Future of Social Cognition. Mahwah, NJ: Lawrence Eribaum Associates.

Jost, J. T., Banaji, M. R., \& Nosek, B. A. (2004). A decade of system justification theory: Accumulated evidence of conscious and unconscious bolstering of the status quo. Political Psychology, 25(6), 881-919. doi:10.1111/j.1467-9221.2004.00402.x

Jury, M., Smeding, A., \& Darnon, C. (2015). Firstgeneration students' underperformance at university: The impact of the function of selection. Frontiers in Psychology, 6, 1-11. doi:10.3389/fpsyg.2015.00710

Jury, M., Smeding, A., Stephens, N. M., Nelson, J. E., Aelenei, C., \& Darnon, C. (2017). The experience of low-SES students in higher education: Psychological barriers to success and interventions to reduce socialclass inequality. Journal of Social Issues, 73(1), 2341. doi:10.1111/josi.12202 
Kim, Y. K., \& Sax, L. J. (2009). Student-faculty interaction in research universities: Differences by student gender, race, social class, and first-generation status. Research in Higher Education, 50(5), 437-459. doi:10.1007/s11162-009-9127-x

Korn, R., Elliot, A. J., \& Daumiller, M. (2018). Back to the roots: Achievement goal standards and standpoints. Unpublished manuscript.

Koza Çiftiçi, Ş., \& Melis Cin, F. (2017). The effect of socioeconomic status on students' achievement. In E. Karadağ (Ed.), The Factors Effecting Student Achievement. Meta-analysis of empirical studies (pp. 171-181). Cham, Switzerland: Springer International Publishing. doi:10.1007/978-3-319-56083-0

Kraus, M. W., Horberg, E. J., Goetz, J. L., \& Keltner, D. (2011). Social class rank, threat vigilance, and hostile reactivity. Personality and Social Psychology Bulletin, 37(10), 1376-1388. doi:10.1177/0146167211410987

Kraus, M. W., \& Park, J. W. (2014). The undervalued self: social class and self-evaluation. Frontiers in Psychology, 5, 1-9. doi:10.3389/fpsyg.2014.01404

Kraus, M. W., \& Park, J. W. (2017). The structural dynamics of social class. Current Opinion in Psychology, 18, 55-60. doi:10.1016/j.copsyc.2017.07.029

Kraus, M. W., Piff, P. K., Mendoza-Denton, R., Rheinschmidt, M. L., \& Keltner, D. (2012). Social class, solipsism, and contextualism: How the rich are different from the poor. Psychological Review, 119(3), 546-572. doi:10.1037/a0028756

Krueger, P. M., Tran, M. K., Saint Onge, J., \& Rogers, R. G. (2016). Occupational prestige, occupational status, and the risk of death in the united states.

Kudrna, L., Furnham, A., \& Swami, V. (2010). The influence of social class salience on self-assessed intelligence. Social Behavior and Personality, 38(6), 859-864. doi:10.2224/sbp.2010.38.6.859

Leopold, L. (1913). Prestige: A psychological study of social estimates. London, UK: T. Fisher Unwin.

Ma, X. (2003). Sense of belonging to school : Can schools make a difference? The Journal of Educational Research, 96(6), 340-349. doi:10.1080/00220670309596617

Maner, J. K. (2017). Dominance and prestige: A tale of two hierarchies. Current Directions in Psychological Science, 26(6), 526-531. doi:10.1177/0963721417714323

Maner, J. K., \& Case, C. R. (2016). Dominance and prestige: Dual strategies for navigating social hierarchies. In J. S. Olson \& M. Zanna (Eds.), Advances in Experimental Social Psychology (54th ed., pp. 129-180). San Diego, CA: Academic Press. doi:10.1016/bs.aesp.2016.02.001

Martin, G. L. (2015). "Always in my face": An exploration of social class consciousness, salience, and values. Journal of College Student Development, 56(19), 471-48746. doi:10.1353/csd.2015.0048

Mok, K. H., \& Wu, A. M. (2016). Higher education, changing labour market and social mobility in the era of massification in China. Journal of Education and Work, 29(1), 77-97. doi: $10.1080 / 13639080.2015 .1049028$

Muller, D., Judd, C. M., \& Yzerbyt, V. Y. (2005). When moderation is mediated and mediation is moderated.
Journal of Personality and Social Psychology, 89(6), 852-63. doi:10.1037/0022-3514.89.6.852

Orbe, M. P. (2004). Negotiating multiple identities within multiple frames: An analysis of first-generation college students. Communication Education, 53(2), 131-149. doi:10.10/03634520410001682401

Ostrove, J. M., \& Long, S. M. (2007). Social class and belonging: Implications for college adjustment. The Review of Higher Education, 30(4), 363-389. doi:10.1353/rhe.2007.0028

Oyserman, D., Coon, H. M., \& Kemmelmeier, M. (2002). Rethinking individualism and collectivism: Evaluation of theoretical assumptions and meta-analyses. Psychological Bulletin, 128(1), 3-72. doi:10.1037//0033-2909.128.1.3

Pittman, L. D., \& Richmond, A. (2007). Academic and psychological functioning in late adolescence: The importance of school belonging. The Journal of Experimental Education, 75(4), 270-290. doi:10.3200/JEXE.75.4.270-292

Ramos-Sánchez, L., \& Nichols, L. (2007). Self-efficacy of first-generation and non-first- generation college students: The relationship with academic performance and college adjustment. Journal of College Counseling, 10(1), 6-18. doi:10.1002/j.21611882.2007.tb00002.x

Reay, D., Crozier, G., \& Clayton, J. (2009). 'Strangers in paradise'?: Working-class students in elite universities. Sociology, 43(6), 1103-1121. doi: $10.1177 / 0038038509345700$

Régner, I., Huguet, P., \& Monteil, J.-M. (2002). Effects of socioeconomic status (SES) information on cognitive ability inferences: When low-SES students make use of a self-threatening stereotype. Social Psychology of Education, 5(3), 253-269. doi:10.1023/A:1016313908667

Ribera, A. K., Miller, A. L., \& Dumford, A. D. (2017). Sense of peer belonging and institutional acceptance in the first year: The role of high-impact practices. Journal of College Student Development, 58(4), 545563. doi:10.1353/csd.2017.0042

Rosseel, Y. (2012). lavaan: An R package for structural equation. Journal of Statistical Software, 48(2), 1-36. Retrieved from http://econpapers.repec.org/article/jssjstsof/v_3a048_ 3ai02.htm

Rubin, M. (2012). Social class differences in social integration among students in higher education: A meta-analysis and recommendations for future research. Journal of Diversity in Higher Education, 5(1), 22-38. doi:10.1037/a0026162

Rubin, M., \& Wright, C. L. (2015). Age differences explain social class differences in students' friendship at university: implications for transition and retention. Higher Education, 70, 427-439. doi:10.1007/s10734014-9844-8

Rubin, M., \& Wright, C. L. (2017). Time and money explain social class differences in students' social integration at university. Studies in Higher Education, 42(2), 315-330. doi:10.1080/03075079.2015.1045481

Shutts, K., Brey, E. L., Dornbusch, L. A., Slywotzky, N., \& Olson, K. R. (2016). Children use wealth cues to evaluate others. PloS One, 11(3), e0149360. doi:10.1371/journal.pone.0149360 
Soria, K. M., \& Stebleton, M. J. (2013). Social capital, academic engagement, and sense of belonging among working-class college students. College Student Affairs Journal, 31(2), 139-153.

Soria, K. M., Stebleton, M. J., \& Huesman, R. L. (2013). Class counts: Exploring differences in academic and social integration between working-class and middle / upper-class students at large, public research universities. Journal of College Student Retention, 15(2), 215-242. doi:10.2190/CS.15.2.e

Spencer, B., \& Castano, E. (2007). Social class is dead. Long live social class! Stereotype threat among low socioeconomic status individuals. Social Justice Research, 20, 418-432. doi:10.1007/s11211-0070047-7

Stebleton, M. J., Soria, K. M., \& Huesman, R. L. (2014). First-generation students' sense of belonging, mental health, and use of counseling services at public research universities. Journal of College Counseling, 17(1), 6-20. doi:10.1002/j.2161-1882.2014.00044.x

Stephens, N. M., Fryberg, S. a., Markus, H. R., Johnson, C. S., \& Covarrubias, R. (2012). Unseen disadvantage: How American universities' focus on independence undermines the academic performance of firstgeneration college students. Journal of Personality and Social Psychology, 102(6), 1178-1197. doi:10.1037/a0027143

Stephens, N. M., Hamedani, M. G., \& Destin, M. (2014). Closing the social-class achievement gap: a difference-education intervention improves firstgeneration students' academic performance and all students' college transition. Psychological Science, 25(4), 943-953. doi:10.1177/0956797613518349

Stephens, N. M., Townsend, S. S. M., Markus, H. R., \& Phillips, L. T. (2012). A cultural mismatch: Independent cultural norms produce greater increases in cortisol and more negative emotions among firstgeneration college students. Journal of Experimental Social Psychology, 48(6), 1389-1393. doi:10.1016/j.jesp.2012.07.008

Terenzini, P. T., Springer, L., Yaeger, P. M., Pascarella, E. T., \& Nora, A. (1996). First-generation college students: Characteristics, experiences, and cognitive development. Research in Higher Education, 37(1), 361-365. doi:10.1007/BF01680039

Tingley, D., Yamamoto, T., Hirose, K., Keele, L., \& Imai, K. (2014). mediation: R package for causal mediation analysis. Journal of Statistical Software, 59(5), 1-38. doi:10.18637/jss.v059.i05
Twenge, J. M., \& Campbell, W. K. (2002). Self-esteem and socioeconomic status: A meta-analytic review. Personality \& Social Psychology Review, 6(1), 59-71. doi:10.1207/s15327957pspr0601

Varnum, M. E. W. (2013). What are lay theories of social class? PloS One, 8(7), e70589. doi:10.1371/journal.pone.0070589

Viechtbauer, W. (2010). Conducting meta-analyses in R with the metafor package. Journal of Statistical Software, 36(3), 1-48. Retrieved from http://brieger.esalq.usp.br/CRAN/web/packages/meta for/vignettes/metafor.pdf

Wallace, A., \& Elliot, A. J., (2018). Retrieval, rereading, and achievement goals. Unpublished manuscript.

Walton, G. M., \& Cohen, G. L. (2007). A question of belonging: Race, social fit, and achievement. Journal of Personality and Social Psychology, 92(1), 82-96. doi:10.1037/0022-3514.92.1.82

Walton, G. M., \& Cohen, G. L. (2011). A brief socialbelonging intervention improves academic and health outocmes of minority students. Science, 331(2011), 1447-1451. doi:10.1126/science. 1198364

Wegener, B. (1992). Concepts and measurement. Annual Review of Sociology, 18, 253-280. doi:10.1146/annurev.so.18.080192.001345

Wiederkehr, V., Darnon, C., Chazal, S., Guimond, S., \& Martinot, D. (2015). From social class to self-efficacy: internalization of low social status pupils' school performance. Social Psychology of Education, 18(4), 769-784. doi:10.1007/s11218-015-9308-8

Yeager, D. S., Walton, G. M., Brady, S. T., Akcinar, E. N., Paunesku, D., Keane, L., ... Dweck, C. S. (2016). Teaching a lay theory before college narrows achievement gaps at scale. Proceedings of the National Academy of Sciences of the United States of America, 113(24), E3341-E3348. doi:10.1073/pnas.1524360113

Yzerbyt, V. Y., Muller, D., \& Judd, C. M. (2004). Adjusting researchers' approach to adjustment: On the use of covariates when testing interactions. Journal of Experimental Social Psychology, 40(3), 424-431. doi:10.1016/j.jesp.2003.10.001

Zhao, L., Lu, Y., Wang, B., Chau, P. Y. K., \& Zhang, L. (2012). Cultivating the sense of belonging and motivating user participation in virtual communities : A social capital perspective. International Journal of Information Management, 32, 574-588. doi:10.1016/j.ijinfomgt.2012.02.006 